\title{
Predictive risk factors for lymph node metastasis in patients with resected non- small cell lung cancer: a case control study
}

\author{
Yusef Moulla ${ }^{1 *} \mathbb{D}$, Tanja Gradistanac ${ }^{2}$, Christian Wittekind ${ }^{2}$, Uwe Eichfeld ${ }^{1}$, Ines Gockel ${ }^{1}$ and Arne Dietrich
}

\begin{abstract}
Background: Estimation of lymph node status is essential in order to determine precise therapy for patients with non-small cell lung cancer (NSCLC). Furthermore, lymph node involvement is a very powerful prognostic factor in these patients. In this analysis, we aim to evaluate the predictive factors for lymph node metastasis in NSCLC-patients.

Methods: In a prospectively-established database, we analyzed all data of patients with NSCLC, who underwent oncological surgical resections from 01/2007 to 12/2016, retrospectively. The correlation between clinicopathological parameters and lymph node metastasis was investigated by using univariate and binary logistic regression analysis.

Results: In this study, we operated on 204 consecutive patients, 142 men (71.7\%) and 56 women (28.3\%). Lymph node metastases were detected in 38.2\% (78/204). Preoperatively, central tumor localization $(\mathrm{OR}=2.6,95 \% \mathrm{Cl}=1.3-5.1$, $P=0.005)$ and tumor size $>3 \mathrm{~cm}(\mathrm{OR}=2.5,95 \% \mathrm{Cl}=1.3-4.4, P=0.005)$ were found to be significant predictive factors for lymph node metastasis. Postoperatively, multivariate analysis showed that intratumoral lymph vessel invasion (L1-status) $(\mathrm{OR}=17.3,95 \% \mathrm{Cl}=5.1-58.4, P<0.001)$ along with the central tumor localization $(\mathrm{OR}=2.8,95 \% \mathrm{Cl}=$ $1.4-5.8, P=0.004)$ were significantly associated with lymph node metastasis. In small size tumors $(\leq 3 \mathrm{~cm})$, two predictive factors for lymph node metastasis were found: central tumor localization $(O R=19.4,95 \%=2.1-186.4$, $P=0.01)$ and $\mathrm{L} 1$-status $(\mathrm{OR}=43.9,95 \% \mathrm{Cl}=3.6-529.4, P=0.003)$.

Conclusions: A precise pre- and intraoperative assessment of the lymph node status is essential in patients with larger sized tumors and central localization. Furthermore, L1-status is a highly significant risk factor for lymph node metastasis in NSCLC-Patients. Therefore, an adjuvant therapy in patients with L1-status and pNX category should be considered.
\end{abstract}

Keywords: Non-small cell lung cancer (NSCLC), Lymph node metastasis, Lymphatic vessel invasion

\section{Background}

Lung cancer is the leading cause of cancer-related death worldwide [1]. The main histological type of lung cancer is non-small lung cancer (NSCLC) (80-85\%). A correctly defined stage of this entity is crucial for therapy planning and estimating of prognosis. The nodal status is considered as one of the most important prognostic factors in NSCLC-patients and, thus, essential in determining the perioperative therapy [2]. Several techniques have been described to detect the clinical N-category, such as

\footnotetext{
* Correspondence: yusef.moulla@medizin.uni-leipzig.de

'Department of Visceral, Transplant, Thoracic and Vascular Surgery, University Hospital of Leipzig, Liebigstraße 20, 04103 Leipzig, Germany

Full list of author information is available at the end of the article
}

radiologic imaging, endoscopic and surgical techniques. The indication to use invasive investigations procedures is always thoroughly discussed to avoid their complications and unnecessary costs. In addition, the extent of intraoperative lymphadenectomy to achieve an accurate staging of NSCLC is by itself a controversial topic. Systematic nodal dissection (SND) with removal of all ipsilateral hilar and mediastinal lymphatic tissue is recommended in oncological lung resection [3]. Other limited node dissection techniques, such as systematic sampling, are considered as effective as SND for accurate staging [4, 5]. As mentioned, it is hard to find the most cost-effective and highest-quality investigation or procedure to accurately determine the stage of the specific lung cancer. In this study, we aimed to

(C) The Author(s). 2019 Open Access This article is distributed under the terms of the Creative Commons Attribution 4.0 International License (http://creativecommons.org/licenses/by/4.0/), which permits unrestricted use, distribution, and reproduction in any medium, provided you give appropriate credit to the original author(s) and the source, provide a link to the Creative Commons license, and indicate if changes were made. The Creative Commons Public Domain Dedication waiver (http://creativecommons.org/publicdomain/zero/1.0/) applies to the data made available in this article, unless otherwise stated. 
identify predictive factors for lymph node metastasis in patients with NSCLC undergoing surgery.

\section{Materials and methods Patients}

All surgically treated NSCLC-patients in curative intent at the University Hospital of Leipzig from 01/2007 to $12 / 2016$ were documented in a prospective database and retrospectively evaluated. Patient's TNM-classifications of the former 6th \&7th edition were transferred into the definitions of 8th edition of American Joint Committee on Cancer (AJCC) by our pathologists in order to gain comparable tumor stages [6]. Only patients, who underwent oncological surgical resections with SND, were analyzed. Exclusion criteria were: (i) Any neoadjuvant therapy or (ii) patients with limited/palliative resections and (iii) those with carcinoid tumors. Clinical staging included mainly Blood tests, Thorax-CT, PET/CT, eventually Brain MRI (symptomatic patients) and Bronchoscopy. Invasive mediastinal staging such as Endobronchial Ultrasound (EBUS) was only done by patients with $\mathrm{cN} 2$, cN3 according to the radiological findings. SND was performed according to the technique as described by Graham et al. [7]. The mediastinal lymph nodes were dissected systematically within anatomical landmarks und labelled with respect to the Mountain \& Dresler map (MD-ATS map) [8] till 2010, and thereafter according to the map of the International Association for Study of Lung Cancer IASLC [9]. The hilar station (No. 10) was dissected before lung resection. Other regional pulmonary lymph nodes (stations No. 11-14) were dissected simultaneously within the resected lung. The dissection of the mediastinal lymph nodes was standardly performed after the resection. For right sided tumors, the lymph nodes stations No. 2, 3 and 4 were removed after opening the mediastinal pleura above the azygos vein. Lymph nodes of the lower mediastinum in stations No. 7, 8 and 9 were dissected after mobilization of the lower lobe. For left-sided tumors, the lymph node dissection was commenced at the aortic arch (stations No. 5 and 6) after locating and conserving the vagal nerve and its branch, the recurrent laryngeal nerve. Then, we proceeded to the dissection to the upper mediastinum (tracheobronchial lymph node stations $2 \& 4)$, which located medial to the subaortic lymph nodes. These lymph nodes could be dissected after mobilization the aortic arch anteriorly (Ligament of Botalli could be divided) and by giving extreme care of the left recurrent laryngeal nerve and left vagal nerve. The Lymph node stations in lower mediastinum (stations No. 7, 8 and 9) were dissected similarly to the right side. The tumor localization was defined as central, if the lesion had been visible endoscopically during preoperative bronchoscopy. The nodal status was worked-up and classified by the pathologist after surgery.
In this study, factors such as age, gender, histological tumor type, tumor site, size, localization and lobe distribution were examined as to their effect on lymph node metastasis in patients with resected NSCLC. Furthermore, histological and morphological parameters, such as pT- category, R-status, lymphatic vessel invasion status (L-status) and venous invasion status (V-status), histological tumor type and grading (G) were investigated postoperatively in terms of their association of lymph node metastasis. We also analyzed the predictive factors for lymph node metastasis in particular in patients with pT1-category, as this cohort is described to develop limited lymph node metastasis only.

\section{Statistical analysis}

To identify potential predictors for pulmonary and mediastinal lymph node metastasis, we used univariate analyses and multivariate binary logistic regression analyses.

In the univariate analysis, Pearson's Chi-square and, if necessary, Fisher exact-test, were used to investigate the correlation of lymph nodes metastasis with categorical variables, and independent sample t-test as well as MannWhitney-U-test, to evaluate this association with continuous/discrete variables.

Patient's variables with $P$-value less than 0.2 were entered stepwise into a multivariate binary logistic regression model, which formed the basis of two prediction models. All factors that reached a significance level of .05 remained in the two final models.

We developed two models for the prediction of lymph node metastasis: The first one for the preoperative phase according to the radiologic und endoscopic findings, and the second one after the surgical resection according to the preoperative findings and the postoperative histopathological reports. We used SPSS (v. 20.0) for Windows 10 for these statistical analyses. All tests were 2 -sided.

\section{Results \\ Patient's characteristics}

Between January 2007 and December 2016, a total of 204 patients with NSCLC fulfilling the inclusion criteria underwent oncologic resection with SND. They were 142 males (71.7\%) and 56 females (28.3\%). The gender ratio (men to women) was [2.5:1]. The median age was 68 years, range [33 to 85 ]. Right sided tumors were observed in $61.8 \%(126 / 204)$ and left sided in $38.2 \%$ (78/204). The right upper lobe was the most frequent localization of tumors with $38.2 \%$ (78/204).

The main procedure in our patient cohort was lobectomy (77.9\%, $n=159)$. Extended resection including bronchoplastic procedures and/or vascular involvement were performed in 17 cases (8.4\%) of all resections. SND was carried out in all patients in a standardzed manner. Histologically, the ratio between adenocarcinoma and squamous 
cell carcinoma (SCC) was 1.5 to 1 (Table 1). The mean size of the tumors was $3.6 \pm 2.2 \mathrm{~cm}$. The median number of dissected lymph nodes was 25 , range [6 to 69]. Tumor

Table 1 Main characteristics of the patients, pTNM-Classification 2017, 8th Edition

\begin{tabular}{|c|c|c|}
\hline Characteristics & Number of Patients (n) & Percentage \\
\hline \multicolumn{3}{|l|}{ Tumor-localization } \\
\hline central & 53 & $26.2 \%$ \\
\hline peripheral & 149 & $73.8 \%$ \\
\hline \multicolumn{3}{|l|}{ Histology } \\
\hline adenocarcinoma & 117 & $57.4 \%$ \\
\hline $\mathrm{sCC}^{\mathrm{a}}$ & 75 & $36.8 \%$ \\
\hline others & 12 & $5.9 \%$ \\
\hline \multicolumn{3}{|l|}{ Grading } \\
\hline In situ & 2 & $1 \%$ \\
\hline G1 & 25 & $12.4 \%$ \\
\hline G2 & 95 & $47.0 \%$ \\
\hline G3 & 68 & $33.3 \%$ \\
\hline G4 & 12 & $5.9 \%$ \\
\hline \multicolumn{3}{|l|}{ pT-category } \\
\hline pTis & 2 & $1 \%$ \\
\hline pT1 & 90 & $45.1 \%$ \\
\hline pT1a & 10 & $4.9 \%$ \\
\hline pT1b & 37 & $18.1 \%$ \\
\hline pT1c & 43 & $21.1 \%$ \\
\hline pT2 & 44 & 26.5 \\
\hline рT2a & 39 & $19.1 \%$ \\
\hline pT2b & 15 & $7.4 \%$ \\
\hline pT3 & 35 & $17.2 \%$ \\
\hline pT4 & 23 & 11.3 \\
\hline \multicolumn{3}{|l|}{ pN-category } \\
\hline pNO & 126 & $61.8 \%$ \\
\hline pN1 & 33 & $16.2 \%$ \\
\hline pN2 & 45 & $22 \%$ \\
\hline \multicolumn{3}{|l|}{ pM-category } \\
\hline pMO & 193 & $94.5 \%$ \\
\hline pM1a & 5 & $2.5 \%$ \\
\hline pM1b & 5 & $2.5 \%$ \\
\hline pM1c & 1 & $0.5 \%$ \\
\hline \multicolumn{3}{|l|}{ pL-Status } \\
\hline pLO & 57 & $28.1 \%$ \\
\hline pL1 & 146 & $71.9 \%$ \\
\hline \multicolumn{3}{|l|}{ pV-Status } \\
\hline pVo & 165 & $81.3 \%$ \\
\hline $\mathrm{pV} 1$ & 38 & $18.7 \%$ \\
\hline
\end{tabular}

${ }^{a}$ SCC Squamous cell carcinoma positive lymph nodes $(\mathrm{pN}+)$ were found in $38.2 \%(78 / 204)$ postoperatively. Pulmonary lymph node metastases $(\mathrm{pN} 1+$, pN2-) were depicted in 16.2\% (33/204). 17.2\% (35/204) of all patients had pulmonary and mediastinal lymph node metastases ( $\mathrm{pN} 1+, \mathrm{pN} 2+)$. A skip-phenomenon (pN1-, pN2+) was observed in 4.9\% (10/204) of patients. Mediastinal lymph node station 4 was the most positive station in all patients with $\mathrm{pN} 2+(20 / 45,44.4 \%)$. pR0-status was confirmed in $93.1 \%$ of all cases (189/204). The postoperative TNM-classification (pTNM) is shown in (Table 1).

\section{Univariate analysis of predictive factors for lymph node metastasis in resected NSCLCs}

Among the investigated parameters, univariate analysis identified the following variables as significant predictors for pulmonary lymph node metastasis (pN1+): Increased tumor size, central tumor localization, pT-category, $\mathrm{R}$-classification, $\mathrm{L}$ - and $\mathrm{V}$-status as well as a higher grading $(P<0.05)$. Other potential parameters, such as age, histological tumor type and further clinicopathological features showed no statistically significant correlation with pulmonary lymph node metastasis (pN1+) (Table 2). The same predictors proved significant for the existence (pulmonary and/or mediastinal) of any lymph node metastasis $(\mathrm{pN}+)$ (Table 3). Furthermore, increased tumor size, central tumor localization, L- and V-status as well higher grading were also identified as significant predictors for mediastinal lymph node metastasis $(\mathrm{pN} 2+)(P<0.05)$ (Table 2$)$.

\section{Multivariate analysis of predictive factors for lymph node metastasis in resected NSCLCs}

The multivariate analysis revealed, according to the preoperative findings, the following significant predictive factors for pulmonary $(\mathrm{pN} 1+)$ and mediastinal (pN2+) lymph node metastasis: Central tumor localization and increased tumor size (Table 4). Furthermore, this multivariate analysis identified tumor size $>3 \mathrm{~cm}$ and central tumor localization as significant factors for any lymph node metastasis $(\mathrm{pN}+)$ (Table 4).

According to the preoperative and postoperative findings, multivariate analysis revealed two significant predictive factors for lymph node metastasis $(\mathrm{pN}+)$ : central tumor localization $(\mathrm{OR}=2.8,95 \% \mathrm{CI}=1.4-5.8, P=0.004)$ and L1-status $(\mathrm{OR}=17.3,95 \% \mathrm{CI}=5.1-58.4, P<0.001)$. Other factors, such as age, histologic tumor type and grading, tumor site, tumor lobe distribution, R-status, V- and Pn-status, did not prove predictive for lymph node metastasis.

\section{Lymph node metastasis in pT1 NSCLCs}

In this study, 90 patients (45.1\%) had a pT1 carcinoma. The median age was 67 years, range [ 45 to 84 ]. There 
Table 2 Univariate Analysis of positive pulmonary and mediastinal lymph nodes (pN1+, pN2+)

\begin{tabular}{|c|c|c|c|c|c|c|}
\hline Variables & pN1- (\%) & $\mathrm{pN} 1+(\%)$ & $P$-Value & pN2- (\%) & $\mathrm{pN} 2+(\%)$ & $P$-Value \\
\hline Sex & & & 0.148 & & & 0.627 \\
\hline male & $90(63.4)$ & $52(36.6)$ & & $112(78.9)$ & $30(21.1)$ & \\
\hline female & $46(74.2)$ & $16(25.8)$ & & $47(75.8)$ & $15(24.2)$ & \\
\hline Age & & & 0.298 & & & 0.237 \\
\hline$\leq 68$ years & $68(63)$ & $40(37)$ & & 88 (81.5) & $20(81.5)$ & \\
\hline$>68$ years & $68(70.8)$ & $28(29.2)$ & & $71(74.0)$ & $25(21.2)$ & \\
\hline Tumor site & & & 0.067 & & & 0.783 \\
\hline right & $90(71.4)$ & 36 (28.6) & & 99 (78.6) & 27 (21.4) & \\
\hline left & $46(59)$ & $32(41)$ & & $60(76.9)$ & $18(23.1)$ & \\
\hline Tumor localization & & & $<0.001$ & & & 0.02 \\
\hline central & $25(47.2)$ & $28(52.8)$ & & $36(66.7)$ & 18 (33.3) & \\
\hline peripheral & $111(74.5)$ & $38(25.5)$ & & $122(81.9)$ & $27(18.1)$ & \\
\hline Tumor size & & & 0.011 & & & 0.042 \\
\hline$\leq 3 \mathrm{~cm}$ & 77 (75.5) & $25(24.5)$ & & $86(84.3)$ & $16(15.7)$ & \\
\hline$>3 \mathrm{~cm}$ & $59(57.8)$ & $43(42.8)$ & & 73 (71.6) & $29(28.4)$ & \\
\hline Lobe distribution & & & 0.918 & & & 0.385 \\
\hline$U L^{a}$ & $85(66.4)$ & 43 (33.6) & & $97(75.8)$ & $31(24.2)$ & \\
\hline Non-UL & $51(67.1)$ & $25(32.9)$ & & $62(81.6)$ & $14(18.4)$ & \\
\hline pT-category & & & 0.015 & & & 0.081 \\
\hline pT1 & 70 (77.8) & $20(22.2)$ & & 77 (85.6) & $13(14.4)$ & \\
\hline pT2 & $33(61.1)$ & $21(38.9)$ & & $40(74.1)$ & $14(25.9)$ & \\
\hline pT3 & $18(51.4)$ & 17 (48.6) & & $23(65.7)$ & $12(34.3)$ & \\
\hline pT4 & $13(56.5)$ & $10(43.5)$ & & $17(73.9)$ & $6(26.1)$ & \\
\hline pR-classification & & & 0.017 & & & 0.088 \\
\hline RO & $130(68.8)$ & $59(31.2)$ & & $150(79.4)$ & 39 (20.6) & \\
\hline $\mathrm{R} 1-2$ & $5(35.7)$ & $9(64.3)$ & & $8(57.1)$ & $6(42.9)$ & \\
\hline pL-status & & & $<0.001$ & & & $<0.001$ \\
\hline pLO & $55(96.5)$ & $2(3.5)$ & & $56(98.2)$ & $1(1.8)$ & \\
\hline pL1 & $80(54.8)$ & $66(45.2)$ & & $102(69.9)$ & $44(30.1)$ & \\
\hline pV-status & & & 0.006 & & & 0.004 \\
\hline pVo & $117(70.9)$ & $48(29.1)$ & & $135(81.1)$ & $30(18.2)$ & \\
\hline $\mathrm{pV}$ & $18(47.4)$ & $20(52.6)$ & & $23(60.5)$ & 15 (39.5) & \\
\hline Pn-Status & & & 0.088 & & & 0.34 \\
\hline Pno & $131(67.9)$ & $62(32.1)$ & & $149(77.2)$ & $44(22.8)$ & \\
\hline Pn1 & $4(40.0)$ & $6(60.0)$ & & $9(90.0)$ & $1(10.0)$ & \\
\hline Histological tumor type & & & 0.214 & & & 0.646 \\
\hline \multirow[t]{2}{*}{ Adeno-Ca. ${ }^{b}$} & $84(71.8)$ & $33(28.2)$ & & $94(80.3)$ & $23(19.7)$ & \\
\hline & & & & $56(74.4)$ & 19 (25.6) & \\
\hline $\mathrm{SCC}^{\mathrm{C}}$ & $45(60.0)$ & $30(40.0)$ & & $9(75.0)$ & $3(25.0)$ & \\
\hline others & $7(58.3)$ & $5(41.7)$ & & & & \\
\hline Grading & & & 0.016 & & & 0.001 \\
\hline G1 & $25(89.3)$ & $3(10.7)$ & & $27(96.4)$ & $1(3.6)$ & \\
\hline $\mathrm{G} 2$ & $64(67.4)$ & $31(32.6)$ & & $79(83.2)$ & $16(16.8)$ & \\
\hline G3 & $39(57.4)$ & $29(42.6)$ & & $43(63.2)$ & $25(36.8)$ & \\
\hline G4 & $7(58.3)$ & $5(41.7)$ & & $9(75.0)$ & $3(25.0)$ & \\
\hline
\end{tabular}

${ }^{\mathrm{a} U L}$ Upper lobe, ${ }^{\mathrm{b}}$ Adeno-Ca. Adenocarcinoma , ${ }^{\mathrm{S} S C C}$ Squamous cell carcinoma 
Table 3 Univariate Analysis of positive lymph nodes (pNo, pN+)

\begin{tabular}{|c|c|c|c|}
\hline Variables & pNO (\%) & $\mathrm{pN}+(\%)$ & $P$-Value \\
\hline Sex & & & 0.397 \\
\hline male & $85(59.9)$ & $57(40.1)$ & \\
\hline female & $41(66.1)$ & $21(33.9)$ & \\
\hline Age & & & 0.314 \\
\hline$\leq 68$ years & $63(58.3)$ & $45(41.7)$ & \\
\hline$>68$ years & $63(65.6)$ & $33(34.4)$ & \\
\hline Tumor site & & & 0.067 \\
\hline Right & $84(66.7)$ & $42(33.3)$ & \\
\hline Left & $42(53.8)$ & $36(46.2)$ & \\
\hline Tumor localization & & & $<0.001$ \\
\hline central & $22(41.5)$ & $31(58.5)$ & \\
\hline peripheral & $104(69.8)$ & $45(30.2)$ & \\
\hline Tumor size & & & $<0.001$ \\
\hline$\leq 3 \mathrm{~cm}$ & $76(74.5)$ & $26(25.5)$ & \\
\hline$>3 \mathrm{~cm}$ & $50(49)$ & $52(51)$ & \\
\hline Lobe distribution & & & 0.834 \\
\hline$U L^{a}$ & $78(60.9)$ & $50(39.1)$ & \\
\hline Non-UL & $40(62.5)$ & $24(37.5)$ & \\
\hline Number of dissected LN ${ }^{b}$ & & & 0.005 \\
\hline pT-category & & & 0.001 \\
\hline pT1 & $69(76.7)$ & $21(23.3)$ & \\
\hline pT2 & $27(50.9)$ & $26(49.1)$ & \\
\hline pT3 & $17(47.2)$ & $19(52.8)$ & \\
\hline pT4 & $11(47.8)$ & $12(52.2)$ & \\
\hline pR-classification & & & 0.048 \\
\hline pRO & $120(96.0)$ & $5(4.0)$ & \\
\hline $\mathrm{pR} 1-2$ & $69(88.5)$ & $9(11.5)$ & \\
\hline pL-status & & & $<0.001$ \\
\hline pLO & $54(94.7)$ & $3(5.3)$ & \\
\hline $\mathrm{pL} 1$ & $71(48.6)$ & $75(51.4)$ & \\
\hline pV-status & & & 0.001 \\
\hline pVo & $111(67.3)$ & $54(32.7)$ & \\
\hline $\mathrm{pV} 1$ & $14(36.8)$ & $24(63.2)$ & \\
\hline Pn-status & & & 0.188 \\
\hline $\mathrm{PnO}$ & $121(96.8)$ & $4(3.2)$ & \\
\hline Pn1 & $72(92.3)$ & $6(7.7)$ & \\
\hline Histological tumor type & & & 0.141 \\
\hline Adeno-Ca. ${ }^{b}$ & $79(67.5)$ & $38(32.5)$ & \\
\hline $\operatorname{scc}^{c}$ & $41(54.7)$ & $34(45.3)$ & \\
\hline others & $6(50.0)$ & $6(50.0)$ & \\
\hline Grading & & & 0.005 \\
\hline G1 & $22(88.0)$ & $3(12.0)$ & \\
\hline G2 & $60(63.2)$ & $35(36.8)$ & \\
\hline G3 & $34(50.0)$ & $34(50.0)$ & \\
\hline G4 & $6(50.0)$ & $6(50.0)$ & \\
\hline
\end{tabular}

${ }^{\mathrm{a} U L}$ Upper lobe, ${ }^{\mathrm{b}}$ Adeno-Ca. Adenocarcinoma, ${ }^{\mathrm{c}}$ SCC Squamous cell carcinoma

were $63.3 \%$ males $(57 / 90)$ and $36.7 \%$ females (33/90). Gender ratio was 1.7:1 (men to women). Right sided tumors were found in $66.7 \%(60 / 90)$. A central tumor localization was detected in 10 patients $(11.1 \%)$. The median tumor size was $2 \mathrm{~cm}$, range [0.4 to $3 \mathrm{~cm}$ ], whereas $52.2 \%$ of the patients displayed tumor size $\leq 2 \mathrm{~cm}(n=47$ / 90). Pathological types were adenocarcinomas $(n=64$, $71.1 \%)$, suqamous cell carcinomas (SCC) $(n=21,23.3 \%)$, and others $(n=5,5.6 \%)$. Grading G3 and G4 were detected in 28 patients with pT1 carcinomas (31.5\%). The median number of dissected lymph nodes was $n=22$, range [6 to 67]. Lymph node metastases $(\mathrm{pN}+)$ were found in 19 patients $(21.1 \%)$, pulmonary lymph node metastases $(\mathrm{pN} 1+)$ in 15 patients (16.6\%), and mediastinal lymph node metastases (pN2+) in 12 patients (13.3\%). L1-status was found in 48 patients of this group (53.3\%).

\section{Univariate and multivariate analysis of predictive factors for lymph node metastasis in pT1 NSCLCs}

The univariate analysis identified the following predictive factors as significant for lymph node metastasis $(\mathrm{pN}+)$ : Central tumor localization $(P=0.005)$, L-status $(P<0.001)$, V-status $(P=0.019)$ and pathological grading $(P=0.009)$. Other clinicopathological parameters, such as age, gender, tumor site, tumor lobe distribution, histological tumor type and the number of dissected lymph nodes did not correlate with a $P$-value $>0.2$. Tumor size was also not significant but had a $P$-value $<0.2(P=0.1)$.

All parameters with a significance level $<0.2$ were included in the multivariate analysis to determine the predictive factors for lymph node metastasis. This analysis revealed only two significant risk factors for lymph node metastasis: central tumor localization $(\mathrm{OR}=19.4$, 95\% CI $=2.1-186.4, P=0.01)$ and $\mathrm{L} 1$ status $(\mathrm{OR}=43.9$, 95\% CI $=3.6-529.4, P=0.003)($ Fig. 1$)$.

\section{Discussion}

We identified increased tumor size and central tumor localization as significant predictive factors for pulmonary and mediastinal lymph node metastasis in resected NSCLCs, according to the preoperative radiologic und endoscopic findings. Furthermore, a tumor size $>3 \mathrm{~cm}$ was in addition to the central tumor localization a significant factor for any lymph node metastasis $(\mathrm{pN}+)$.

In an analysis of 566 patients (175 patients with $\mathrm{pN} 2+$ ), Shafazand et al. [10] found tumor size $>3.6 \mathrm{~cm}$ and central tumor localization as significant predictive factors for lymph node metastasis. This study also identified age of $<65$ years and histological tumor type (adenocarcinoma or large cell) as predictive factors for lymph node metastasis. Another retrospective analysis of 379 patients (68 with pN2) by Suzuki et al. [11] demonstrated that tumor size $>2.0 \mathrm{~cm}$, high serum carcinomembryonic antigen (CEA) level and the histopathological tumor type (adenocarcinoma) were predictive factors for mediastinal lymph node metastasis. In our study, we could not identify age or the pathological entity as predictive 
Table 4 Multivariate analysis of predictive factors for lymph node metastasis (preoperative model)

\begin{tabular}{|c|c|c|c|}
\hline Predictive factors & Pulmonary $L N^{a}$ metastasis $(p N 1+)$ & Mediastinal LN a metastasis (pN2+) & Any $L N^{a}$ metastasis $(\mathrm{pN}+)^{\mathrm{e}}$ \\
\hline Central localization & $\begin{array}{l}P=0.002^{b} \\
\mathrm{OR}=2.9^{c} \\
\mathrm{Cl}=1.5-5.6^{\mathrm{d}}\end{array}$ & $\begin{array}{l}P=0.06 \\
\text { OR2.0 } \\
C l=0.9-4.1\end{array}$ & $\begin{array}{l}P=0.005 \\
O R=2.6 \\
C l=1.3-5.1\end{array}$ \\
\hline Increased tumor size & $\begin{array}{l}P=0.043 \\
\mathrm{OR}=1.2 \\
\mathrm{Cl}=1.0-1.3\end{array}$ & $\begin{array}{l}P=0.040 \\
O R=1.2 \\
C I=1.0-1.4\end{array}$ & $\begin{array}{l}P=0.005 \\
\mathrm{OR}=2.5 \\
\mathrm{Cl}=1.3-4.4\end{array}$ \\
\hline
\end{tabular}

${ }^{\mathrm{a}} \mathrm{LN}$ Lymph node, ${ }^{\mathrm{b}} \mathrm{P} P$-Value, ${ }^{\mathrm{C} O R}$ Odds ratio, $\mathrm{Cl} 95 \%,{ }^{\mathrm{d}} \mathrm{Cl}$ Confidence interval, ${ }^{\mathrm{e}}$ Patients were divided in two groups according to tumor size ( $>3 \mathrm{~cm}$ and $\left.\leq 3 \mathrm{~cm}\right)$

factors for any lymph node metastasis. Unfortunately, CEA level was not available in our database and, thus, not included in the current analysis. However, this serum tumor marker has been described in previous studies as a predictive factor for advanced disease and worse prognosis [12]. Graham et al. [7] detected younger age, increased tumor diameter, left lower lobe origin and bronchial origin as significant predictive factors for lymph node metastasis in resected NSCLCs. In our study, tumor localization in lower left lobe (LLL) proved without any influence on lymph node metastasis $(P=0.448)$ and, thus, we were unable to replicate these data found by Graham et al.

Accurate mediastinal staging in patients with operable NSCLCs preoperatively and postoperatively is very essential to guide the treatment and to determine the extent of disease and consequently the patients prognosis. This staging can be performed through radiologic, endoscopic and surgical techniques. Previous meta-analyses have already shown that the use of thorax-CT in assessing the $\mathrm{cN}$-category has a sensitivity of $60-83 \%$, a specificity of $77-82 \%$ and a negative predictive value of $80-85 \%[13,14]$.

Another meta-analysis compared PET/CT and diffusionweighted magnetic resonance imaging (DW-MRI) technique in detecting the mediastinal lymph node metastasis preoperatively [15]. Sensitivity was low at $65 \%$ for PET/ CT and $72 \%$ for DWI, while specificity was high $(93 \%$ vs. 97\%). Overall, the assessment of lymph node micrometastasis by radiologic investigations is not reliable. Endoscopic procedures, such as Endobronchial Ultrasound (EBUS) with Transbronchial Needle Aspiration (TBNA), provide more accurate information about the mediastinal staging, with a sensitivity of $83-94 \%$ [16]. Surgical techniques, such as video-assisted mediastinoscopy (VAM) (accuracy 88-99\%) and video-assisted mediastinal lymphadenectomy (VAMLA) (accuracy 100\%) have the highest accuracy with respect to the preoperative mediastinal staging. However, these techniques have a morbidity rate of $3.5 \%$ [17]. Intraoperative evaluation of nodal status at the hilar and mediastinal stations is known to be a very important tool for accurate staging [18]. As mentioned above, the pathological examination of dissected lymph nodes revealed the most precise assessment of nodal status in patients with NSCLCs.

The necessary extent of lymph node dissection in the treatment of NSCLC remains controversial [18, 19]. Some authors have reported performing SND in all oncological resections of NSCLC [20,21]. Others have recommended systematic mediastinal lymph node sampling (MLNS) or lobe-specific node dissection as good options

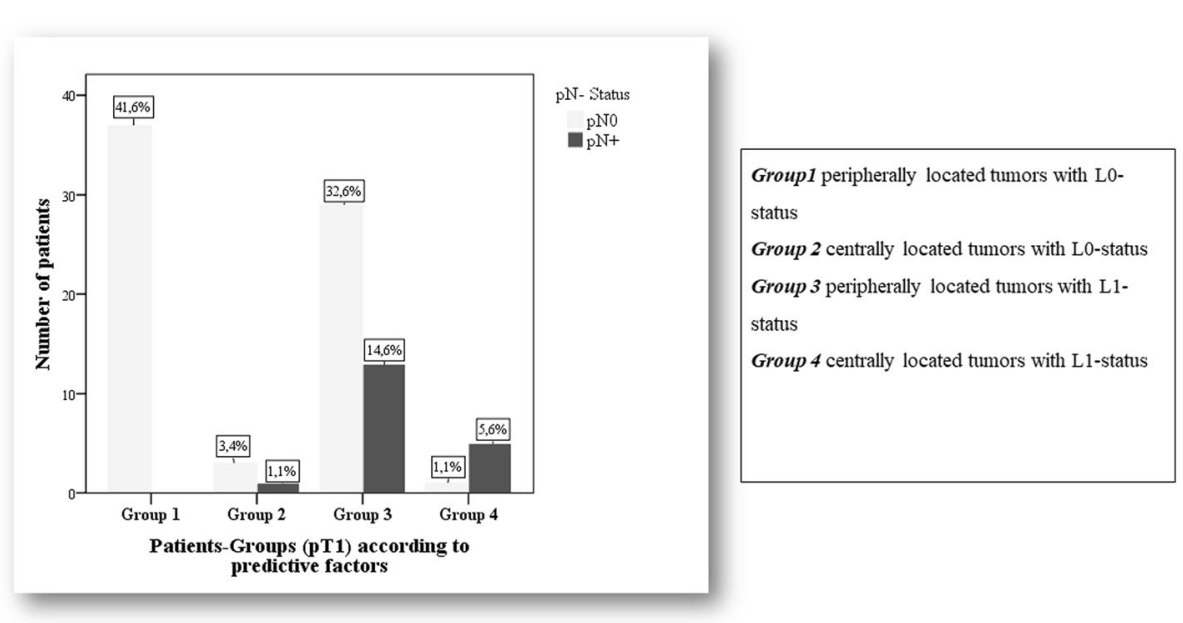

Fig. 1 pN-category in patients with pT1-tumors according to predictive risk factors 
in operable NSCLCs, in order to estimate the lymph node status and to reduce the perioperative morbidity and mortality $[4,22]$. While the effectiveness of SND to improve local tumor control and to achieve accurate staging has already been established, the benefit of SND regarding prognosis is yet to be proven [3]. Keller et al. [23] demonstrated improved survival and detection of more positive N2 lymph nodes (upstaging) through SND than with MLNS. Furthermore, Shapiro et al. [24] found similar survival rates in a lobe specific lymph node dissection group as compared to the SND group, following either lobectomy via thoracoscopy (VATS) or thoracotomy in clinically negative N2 patients. Minimally invasive surgery has widely been established as an appropriate surgical choice for early stage NSCLC patients, but the extent and feasibility of lymph node dissection during minimally invasive thoracic surgery in patients with clinically negative N2 disease still remains a controversial topic. Toker et al. [25] proved that minimally invasive thoracic surgery, including robotic assisted thoracic surgery, can harvest a similar number of lymph nodes as compared to open surgery. Other authors, such as Merritt et al. [26], found a significantly higher mean number of dissected lymph nodes by open lobectomy than by VATS-lobectomy. In addition, the overall pathological upstaging of the $\mathrm{pN}$-status was significantly higher in the open lobectomy group [26].

Considering the above-mentioned studies and our own results, we would suggest that a more precise preoperative or intraoperative assessment of all lymph node stations in patients with large size tumors and/or with central tumor localization is mandatory. The surgical technique used should not prevent a precise assessment of hilar and mediastinal lymph nodes. We therefore insist on the following recommendation of the European Society of Thoracic Surgery (ESTS) guidelines, which state, that the most sensitive procedures (endoscopic and surgical), even when invasive, should be performed to achieve an accurate mediastinal staging in patients with centrally located and/or large size $(>3 \mathrm{~cm})$ tumors [17]. Following our results from this study and in consideration of those from others, $[17,18]$ we started applying the algorithm shown in Fig. 2 in our department, in order to achieve a precise preoperative and intraoperative assessment of lymph node metastasis in patients with high risk factors.

In this study, we identified the rate of lymph node metastasis in patients with small size tumors (pT1 carcinomas) to be approximately $20 \%$, which is similar to other international studies [27]. The necessary extent of surgical resection, preoperative mediastinal staging and intraoperative lymph node dissection in small size tumors $(\leq 3 \mathrm{~cm})$ is another controversial topic. L1-status and central localization were found to be significant predictive factors for the existence of lymph node metastases. However, tumor localization can be detected easily preoperatively. This information can help us in advance to determine the appropriate procedure and the extent of surgical resection and lymphadenectomy. Many studies have recommended a limited surgical resection (e.g. segmentectomy) to be oncologically adequate in patients with small size tumors (T1 carcinomas) [28, 29]. However, the precise assessment of pulmonary lymph nodes in limited resections is still a field of debate in the surgical community. Therefore, limited surgical resections in patients with centrally located tumors are not recommended so far, as these do not allow for efficient dissection of pulmonary and hilar lymph nodes. The need for invasive mediastinal staging (endoscopic $-/+$ surgical techniques) in patients with centrally located small size tumors should be evaluated in accordance with the results of this study.

The other parameter (L-status) is rarely found in the preoperative pathological reports. The presence of L1-status is associated with a higher rate of local recurrence and a worse overall survival in early lung cancer [30]. Higgins et al. [31] described L1-status as a risk factor for regional lymph node involvement as well as a poor prognostic factor in NSCLC-patients. Such informations can be useful in determining the recommended treatment in patients who have undergone limited resection without complete dissection of the regional and mediastinal lymph nodes (pNX-category), or in patients

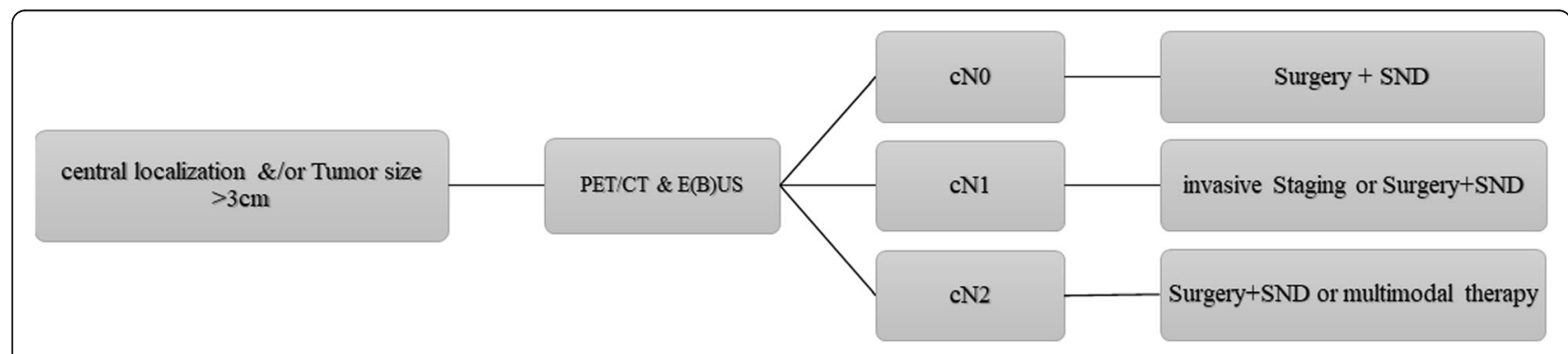

Fig. 2 Suggested algorithm to achieve a precise assessment of lymph node metastasis in NSCLC patients with risk factors 
scheduled to undergo stereotactic ablative radiotherapy (SABR). However, adjuvant chemotherapy can also be discussed in these patients. Furthermore, improving in the core needle technique, which could provide more tissue to be examined, might be useful in enhancing the detection rate of L-positive patients preoperatively.

The aim of this study was to evaluate the risk factors of lymph node metastasis in operable NSCLSs, and, consequently, to evaluate oncologically adequate treatment strategies. Limitations of this study are retrospective analyses and non-inclusion of potentially prognostic parameters such as CEA, which were not available.

\section{Conclusions}

NSCLC-patients with larger size tumors and central tumor localization require a precise preoperative and intraoperative assessment of their lymph node status, as these patients have an increased risk of lymph node metastasis. L1-status is a risk factor for lymph node metastasis in NSCLCs, irrespective of tumor size. In a situation with no sufficient postoperative lymph status (pNX), this risk factor should be considered when determining the postoperative (adjuvant) treatment. However, further studies are required to investigate the effects of adjuvant chemotherapy in cases with L1-status.

\section{Abbreviations \\ CEA: Serum carcinomembryonic antigen; EBUS: Endobronchial Ultrasound; IASLC: International Association for Study of Lung Cancer; MD-ATS map: Mountain, Dresler -American Thoracic Society map; MLNS: Mediastinal lymph node sampling; NSCLC: Non-small cell lung cancer; SABR: Stereotactic ablative radiotherapy; SCC: Suqamous cell carcinomas; SND: Systematic node dissection; TBNA: Transbronchial Needle Aspiration; VAM: Video-assisted mediastinoscopy; VAMLA: Video-assisted mediastinal lymphadenectomy; VATS: Video-assisted thoracoscopy}

\section{Acknowledgements}

We acknowledge support from the German Research Foundation (DFG) and Leipzig University within the program of Open Access publishing.

\section{Funding}

None

Availability of data and materials

All data analyzed during this retrospective study are included in this article.

\section{Authors' contributions}

YM collected and analyzed the data, interpreted the results and wrote the paper, IG participated in the design of study and drafted the manuscript. AD coordinated, revised and drafted the study. Other Authors have read and approved the final version of manuscript.

\section{Ethics approval and consent to participate}

For this type of study formal consent is not required.

\section{Consent for publication}

For this type of study formal consent is not required.

\section{Competing interests}

The authors declare that they have no competing interests.

\section{Publisher's Note}

Springer Nature remains neutral with regard to jurisdictional claims in published maps and institutional affiliations.

\section{Author details}

'Department of Visceral, Transplant, Thoracic and Vascular Surgery, University Hospital of Leipzig, Liebigstraße 20, 04103 Leipzig, Germany. ${ }^{2}$ Institute of Pathology, University Hospital of Leipzig, Liebigstraße 20, 04103 Leipzig, Germany.

Received: 19 May 2018 Accepted: 8 January 2019

Published online: 16 January 2019

\section{References}

1. Siegel R, Naishadham D, Jemal A. Cancer statistics, 2013. CA Cancer J Clin. 2013;63(1):11-30.

2. Asamura $\mathrm{H}$, et al. The International Association for the Study of Lung Cancer lung Cancer staging project: proposals for the revision of the $\mathrm{N}$ descriptors in the forthcoming 8th edition of the TNM classification for lung Cancer. J Thorac Oncol. 2015;10(12):1675-84.

3. Lardinois $D$, et al. ESTS guidelines for intraoperative lymph node staging in non-small cell lung cancer. Eur J Cardiothorac Surg. 2006;30(5):787-92.

4. Izbicki JR, et al. Effectiveness of radical systematic mediastinal lymphadenectomy in patients with resectable non-small cell lung cancer: results of a prospective randomized trial. Ann Surg. 1998;227(1):138-44.

5. Darling GE, et al. Randomized trial of mediastinal lymph node sampling versus complete lymphadenectomy during pulmonary resection in the patient with N0 or N1 (less than hilar) non-small cell carcinoma: results of the American college of surgery oncology group Z0030 trial. J Thorac Cardiovasc Surg. 2011;141(3):662-70.

6. Detterbeck FC, et al. The eighth edition lung Cancer stage classification. Chest. 2017;151(1):193-203.

7. Graham AN, et al. Systematic nodal dissection in the intrathoracic staging of patients with non-small cell lung cancer. J Thorac Cardiovasc Surg. 1999;117(2):246-51.

8. Mountain CF, Dresler CM. Regional lymph node classification for lung cancer staging. Chest. 1997;111(6):1718-23.

9. Edge SB, Compton CC. The American joint committee on Cancer: the 7th edition of the AJCC cancer staging manual and the future of TNM. Ann Surg Oncol. 2010;17(6):1471-4.

10. Shafazand S, Gould MK. A clinical prediction rule to estimate the probability of mediastinal metastasis in patients with non-small cell lung cancer. J Thorac Oncol. 2006; 1 (9):953-9.

11. Suzuki K, et al. Clinical predictors of N2 disease in the setting of a negative computed tomographic scan in patients with lung cancer. J Thorac Cardiovasc Surg. 1999:117(3):593-8.

12. Takamochi $\mathrm{K}$, et al. Clinical predictors of $\mathrm{N} 2$ disease in non-small cell lung cancer. Chest. 2000;117(6):1577-82.

13. Dales RE, Stark RM, Raman S. Computed tomography to stage lung cancer. Approaching a controversy using meta-analysis. Am Rev Respir Dis. 1990; 141(5 Pt 1):1096-101.

14. Dwamena BA, et al. Metastases from non-small cell lung cancer: mediastinal staging in the 1990s--meta-analytic comparison of PET and CT. Radiology. 1999;213(2):530-6.

15. Shen G, et al. Correction: comparison of 18F-FDG PET/CT and DWI for detection of mediastinal nodal metastasis in non-small cell lung cancer: a meta-analysis. PLoS One. 2017;12(4):e0176150.

16. Chandra S, et al. Diagnostic accuracy of endobronchial ultrasound-guided transbronchial needle biopsy in mediastinal lymphadenopathy: a systematic review and meta-analysis. Respir Care. 2012;57(3):384-91.

17. De Leyn P, et al. Revised ESTS guidelines for preoperative mediastinal lymph node staging for non-small-cell lung cancer. Eur J Cardiothorac Surg. 2014:45(5):787-98.

18. Watanabe S. Lymph node dissection for lung cancer: past, present, and future. Gen Thorac Cardiovasc Surg. 2014;62(7):407-14.

19. Zhong W, et al. Complete mediastinal lymphadenectomy: the core component of the multidisciplinary therapy in resectable non-small cell lung cancer. Eur J Cardiothorac Surg. 2008;34(1):187-95.

20. Massard $\mathrm{G}$, et al. Sampling or node dissection for intraoperative staging of lung cancer: a multicentric cross-sectional study. Eur J Cardiothorac Surg. 2006;30(1):164-7. 
21. Passlick B, et al. Mediastinal lymphadenectomy in non-small cell lung cancer: effectiveness in patients with or without nodal micrometastases results of a preliminary study. Eur J Cardiothorac Surg. 2002;21(3):520-6.

22. Grupo Cooperativo de Carcinoma Broncogencio de la Sociedad Espanola de Neumologia y Cirugia, T. Intraoperative lymph node staging in bronchogenic carcinoma surgery. Consensus report. Arch Bronconeumol. 2001;37(11):495-503.

23. Keller $\mathrm{SM}$, et al. A randomized trial of postoperative adjuvant therapy in patients with completely resected stage II or IIIA non-small-cell lung cancer. Eastern cooperative oncology group. N Engl J Med. 2000;343(17):1217-22.

24. Shapiro M, et al. Lobe-specific mediastinal nodal dissection is sufficient during lobectomy by video-assisted thoracic surgery or thoracotomy for early-stage lung cancer. Chest. 2013;144(5):1615-21.

25. Toker $\mathrm{A}$, et al. Lymph node dissection in surgery for lung Cancer: comparison of open vs. video-assisted vs. robotic-assisted approaches. Ann Thorac Cardiovasc Surg. 2016;22(5):284-90.

26. Merritt RE, Hoang CD, Shrager JB. Lymph node evaluation achieved by open lobectomy compared with thoracoscopic lobectomy for No lung cancer. Ann Thorac Surg. 2013;96(4):1171-7.

27. Zhang YK, et al. Association of lymph node involvement with the prognosis of pathological T1 invasive non-small cell lung cancer. World J Surg Oncol. 2017:15(1):64.

28. Bao F, et al. Segmentectomy or lobectomy for early stage lung cancer: a meta-analysis. Eur J Cardiothorac Surg. 2014;46(1):1-7.

29. Yamashita S, et al. Clinical impact of segmentectomy compared with lobectomy under complete video-assisted thoracic surgery in the treatment of stage I non-small cell lung cancer. J Surg Res. 2011;166(1):46-51.

30. Mimae T, et al. Role of lymphatic invasion in the prognosis of patients with clinical node-negative and pathologic node-positive lung adenocarcinoma. J Thorac Cardiovasc Surg. 2014;147(6):1820-6.

31. Higgins KA, et al. Lymphovascular invasion in non-small-cell lung cancer: implications for staging and adjuvant therapy. J Thorac Oncol. 2012;7(7): $1141-7$.

Ready to submit your research? Choose BMC and benefit from:

- fast, convenient online submission

- thorough peer review by experienced researchers in your field

- rapid publication on acceptance

- support for research data, including large and complex data types

- gold Open Access which fosters wider collaboration and increased citations

- maximum visibility for your research: over $100 \mathrm{M}$ website views per year

At $\mathrm{BMC}$, research is always in progress.

Learn more biomedcentral.com/submissions 